\title{
Experimental research of punching shear mechanism of reinforcing concrete slab
}

\author{
Nikolay Trekin ${ }^{1}$, and Dmitrii Pekin ${ }^{2}$ \\ ${ }^{1}$ Moscow State University of Civil Engineering, Yaroslavskoe shosse, 26, Moscow, 129337, Russia \\ ${ }^{2}$ LLC «INV-STROY», Moscow, Russia
}

\begin{abstract}
The analysis of various regulatory methods for calculating reinforced concrete slabs for pushing and comparing with experiment results is made. The tested sample, measuring equipment and test bench are described. Sizes and materials for experimental prototype were chosen by existing beamless and capless slabs of monolithic reinforced concrete superstructures with column grid from $8 \times 8$ to $9 \times 9 \mathrm{~m}$.

Experimental research results of reinforcing concrete plate structure are presented for study purpose of stress-strain state when punching shear collapse occurring. Various aspects and observations obtained during the test are given. The comparison of the tested slab fragment with the complete response of slab structure is performed.

Analysis of tested sample stress-strain state and punching bearing capacity calculations results in according to existing regular standards were made. Main criterias of punching shear collapse were determined and new procedure for punching calculation of RC concrete slabs was offered basing on significantly new approach in punching bearing capacity defining.
\end{abstract}

\section{Introduction}

The study of the mechanism of punching reinforced concrete slab structures on the basis of theoretical studies, field experiments and comparison of the strength calculation results using various techniques implemented in SNiP 2.03.01-84 *, SP 63.13330.2012 and Eurocode 2, has been actively pursued in the last few years [1-5].

They criticize the current provisions of domestic standards in terms of calculating punching in the presence of shear reinforcement, which summarize the bearing concrete capacity at SSS stage I and the bearing shear reinforcement capacity at SSS stage III, which obviously does not correspond to the physical nature of the destruction mechanism. It should also be noted that there are other shortcomings of the standard methods of punching calculation according to SP 63.13330.2012:

- the experiment results [3] show that the standard calculation method leads to a significant overestimation of the bearing punching capacity using high-strength concrete class B40, B45;

*Corresponding authors: otks@narod.ru; dpekin@mail.ru 
- the conducted tests [4] show that, when increasing the die block dimensions, the standard calculation method also leads to an overestimation of the bearing punching capacity;

- there is no consideration of the actual SSS pattern of the slab reinforced concrete structure support zones [5] including longitudinal reinforcement in the compression and tension zones, asymmetric stress state in orthogonal directions and on different column faces, loading mode;

- the accounting method of the column torque when calculating floor slabs for punching has some contradictions;

- the design requirement set forth in clauses 8.1.46 and 10.3.17, in contrast to the requirements of SNiP 2.03.01-84*, for placing shear reinforcement in the plan at a distance of at least $\mathrm{h}_{0} / 3$ from the column faces (cargo area) for large thickness slab structures can lead to the implementation of the "constrained" punching mechanism, by analogy with the pile cap destruction;

- there are no recommendations for the calculation of the soil reactive pressure for base plates, in contrast to the method of SNiP 2.03.01-84* and Eurocode 2,

- $\quad$ and according to Eurocode 2:

- fully empirical determination of ultimate shear stresses in concrete based on the cube strength;

- uniform distribution of tangential stresses at the working section height, and not at the height of the compression concrete;

- a significant underestimation of the bearing punching capacity of the studied sample.

The punching mechanism is one of the most dangerous types of slab reinforced concrete structure destruction and depends on a large number of factors. Due to this fact, the further study of issues related to the punching mechanism implementation and the coverage of new unexplored destruction aspects is an important task, especially when a wide range of specialists are provided with test results of a monolithic reinforced concrete slab for punching with a sufficiently detailed sample description and experiment conducted previously for comparison with the new design of the beamless slab reinforced by a hidden metal capital [6] at the rigid connection.

\section{Experimental researches}

\subsection{Test bench and loading procedure description}

The supporting contour was made with dimensions in terms of $2.16 \times 2.16 \times 0.24(\mathrm{~h}) \mathrm{m}$ from a paired channel No. 24 of box-shaped cross-section to counduct tests. The supporting contour was installed on 8 posts of $1.2 \mathrm{~m}$ height, basing on reinforced floor. The slab sample has been installed on the centrifugal solution with a support length of $100 \mathrm{~mm}$ along the supporting contour. The punching was carried out through a loading plate with 4 hydraulic energizers from a common collector, capable of creating a force of $1000 \mathrm{kN}$ each. The total weight of the equipment, applied before the experiment start, was 8 tons. Then, the punching applied to the coating fragment through the column was changed stepwise, increasing by $200 \mathrm{kN}$ with an interval of 20 minutes, immediately before the destruction moment. The photographs of the described test with the test sample are shown in Figure 1.

\subsection{Sample description}

The slab fragment manufacture uses heavy concrete of class B30 and reinforcement of class A500C $18 \varnothing 12 \mathrm{~mm}$ with a pitch of $100 \mathrm{~mm}$ in two directions in the lower zone at a distance 
of $25 \mathrm{~mm}$ from the center of 1 row of reinforcement to the plate face. The overall slab fragment dimensions are $2.0 \times 2.0 \times 0.24(\mathrm{~h}) \mathrm{m}$. The column head was made in the form of a cube with a side size of $0.5 \mathrm{~m}$ and constructive reinforcement of the longitudinal (4Ø16 $\mathrm{mm})$ and shear reinforcement (5Ø8 $\mathrm{mm}$ with an interval of $100 \mathrm{~mm}$ ).

\subsection{Measuring equipment description}

The reinforcing bars were equipped with two 2PKB-10 resistive-strain sensors (RSS-3) from the each side of the bar as shown in Figure 2. The reinforcement surface was preliminarily prepared for gluing by means of arranging flat pads placed parallel to each other from different sides. The compression concrete in the alignment with characteristic reinforcing bars was equipped with PL-60-11 resistive-strain sensors (RSS-2) with an interval of $100 \mathrm{~mm}$ as shown in Figure 2. The concrete surface was also preliminarily prepared for the gluing of resistive-strain sensors by means of flat pads arranged parallel to each other. The Vt-718-15 (0-30 mm) motion sensor (MS-1) was installed in the center of the lower sample edge to determine the deflections. Moreover, The PCE-MM200 electron microscope was installed on one of the column faces on the lower slab surface near the location of the resistive-strain sensors 3,4;30 for measuring the opening of normal crack width using the subsequent comparison with the standard line of $0.4 \mathrm{~mm}$ thickness on the measuring line (Elcometer 143).

Tables 1-3 show the indications of resistive-strain sensors, installed on the reinforcement and concrete, as well as the indicators of the motion sensor and the electron microscope as the sample is punched with a stepwise increasing load.

\subsection{Measurement results}

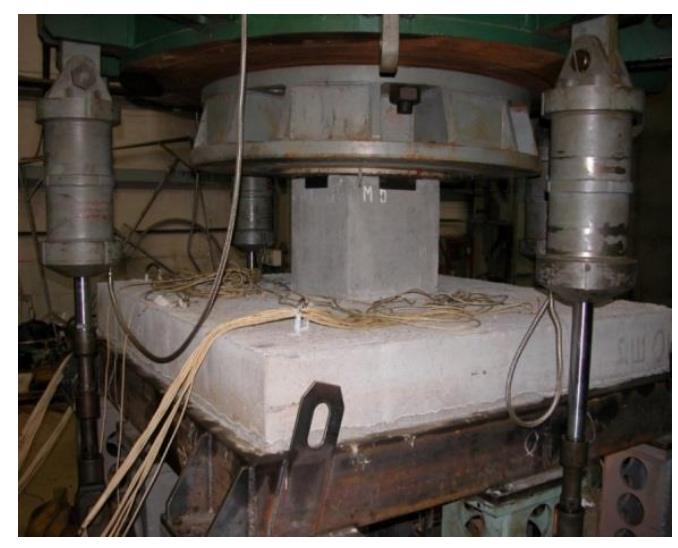

a) sample on the bench, side view

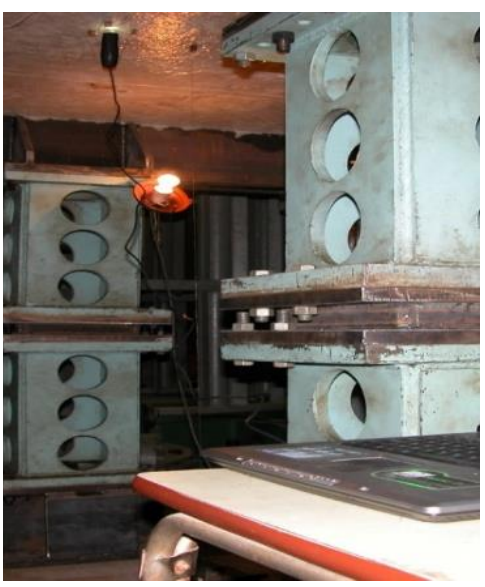

b) sample on the bench, view from below

Fig. 1. Test bench 


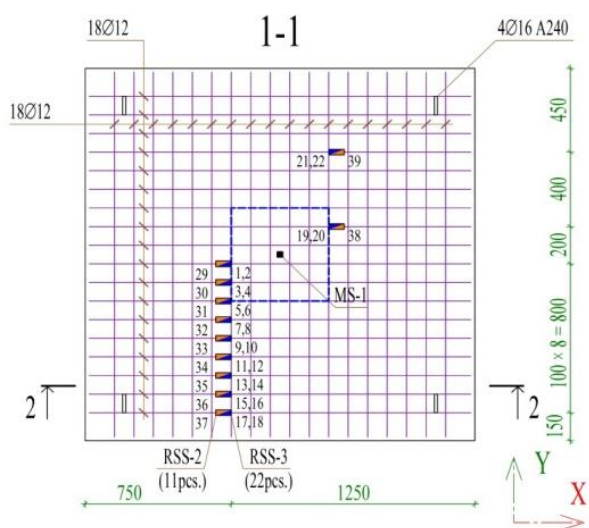

a) plan view

Fig.2. Slab fragment

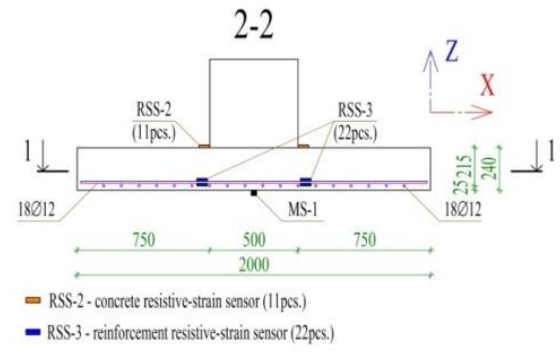

b) side view

Table 1. Reinforcement resistive-strain sensor data

\begin{tabular}{|c|c|c|c|c|c|c|c|}
\hline \multirow{2}{*}{ Sensor No. } & \multicolumn{7}{|c|}{ Resistive-strain sensor relative deformations $\boldsymbol{\varepsilon}, \boldsymbol{\%}$} \\
\cline { 2 - 9 } & $\mathbf{8 0} \mathbf{~ k N}$ & $\mathbf{2 8 0} \mathbf{~ k N}$ & $\mathbf{4 8 0} \mathbf{~ k N}$ & $\mathbf{6 8 0} \mathbf{~ k N}$ & $\mathbf{8 8 0} \mathbf{~ k N}$ & $\mathbf{1 0 8 0} \mathbf{~ k N}$ & $\mathbf{1 1 8 0} \mathbf{~ k N}$ \\
\hline RSS -3-1 & - & 0.047 & 0.134 & 0.209 & 0.254 & 0.338 & - \\
\hline RSS -3-2 & - & 0.045 & 0.140 & 0.208 & 0.254 & 0.409 & - \\
\hline RSS -3-3 & - & 0.036 & 0.121 & 0.186 & 0.233 & 0.357 & - \\
\hline RSS -3-4 & - & 0.041 & 0.126 & 0.190 & 0.234 & - & - \\
\hline RSS -3-5 & - & 0.038 & 0.143 & - & - & - & - \\
\hline RSS -3-6 & - & 0.037 & 0.118 & 0.184 & 0.237 & 0.369 & - \\
\hline RSS -3-7 & - & - & - & - & - & - & - \\
\hline RSS -3-8 & - & 0.032 & 0.103 & 0.170 & 0.234 & 0.299 & - \\
\hline RSS -3-9 & - & 0.037 & 0.093 & 0.150 & 0.213 & 0.298 & - \\
\hline RSS -3-10 & - & 0.079 & 0.162 & 0.354 & 0.443 & 0.570 & - \\
\hline RSS -3-11 & - & 0.042 & 0.096 & 0.147 & 0.199 & 0.268 & - \\
\hline RSS -3-12 & - & 0.031 & 0.079 & 0.122 & 0.173 & 0.234 & - \\
\hline RSS -3-13 & - & 0.037 & 0.086 & 0.120 & 0.148 & 0.226 & - \\
\hline RSS -3-14 & - & 0.039 & 0.086 & 0.121 & 0.151 & 0.211 & - \\
\hline RSS -3-15 & - & 0.031 & 0.071 & 0.107 & 0.136 & 0.187 & - \\
\hline RSS -3-16 & - & 0.023 & 0.056 & 0.083 & 0.110 & 0.164 & - \\
\hline RSS -3-17 & - & -0.005 & -0.002 & 0 & 0.010 & 0.040 & - \\
\hline RSS -3-18 & - & 0.021 & 0.043 & 0.109 & 0.133 & 0.182 & - \\
\hline RSS -3-19 & - & 0.098 & 0.228 & - & - & - & - \\
\hline RSS -3-20 & - & 0.034 & 0.115 & 0.187 & 0.243 & 0.337 & - \\
\hline RSS -3-21 & - & 0.024 & 0.059 & 0.092 & 0.120 & 0.175 & - \\
\hline RSS -3-22 & - & 0.022 & 0.064 & 0.125 & 0.171 & 0.234 & - \\
\hline
\end{tabular}


Table 2. Concrete resistive-strain sensor data

\begin{tabular}{|c|c|c|c|c|c|c|c|}
\hline \multirow{2}{*}{ Sensor No. } & \multicolumn{7}{|c|}{ Relative concrete sensor deformations $\boldsymbol{\varepsilon}, \%$} \\
\cline { 2 - 9 } & $\mathbf{8 0} \mathbf{~ k N}$ & $\mathbf{2 8 0} \mathbf{~ k N}$ & $\mathbf{4 8 0} \mathbf{~ k N}$ & $\mathbf{6 8 0} \mathbf{~ k N}$ & $\mathbf{8 8 0} \mathbf{~ k N}$ & $\mathbf{1 0 8 0} \mathbf{~ k N}$ & $\mathbf{1 1 8 0} \mathbf{~ k N}$ \\
\hline RSS -2-29 & - & 0.024 & 0.019 & 0.018 & 0.026 & 0.049 & - \\
\hline RSS -2-30 & - & 0.012 & 0.001 & -0.005 & 0.001 & 0.03 & - \\
\hline RSS -2-31 & - & 0.007 & -0.003 & -0.011 & -0.004 & 0.031 & - \\
\hline RSS -2-32 & - & 0.015 & 0.006 & 0.001 & -0.007 & -0.019 & - \\
\hline RSS -2-33 & - & -0.016 & -0.038 & -0.053 & -0.073 & -0.099 & - \\
\hline RSS -2-34 & - & 0.019 & 0.016 & 0.014 & 0.003 & -0.012 & - \\
\hline RSS -2-35 & - & - & - & - & - & - & - \\
\hline RSS -2-36 & - & 0 & -0.007 & -0.015 & -0.021 & -0.025 & - \\
\hline RSS -2-37 & - & - & - & - & - & - & - \\
\hline RSS -2-38 & - & -0.018 & -0.04 & -0.061 & -0.072 & -0.059 & - \\
\hline RSS -2-39 & - & -0.028 & -0.052 & -0.083 & -0.101 & -0.124 & - \\
\hline
\end{tabular}

Table 3. Vertical motion data

\begin{tabular}{|c|c|c|c|c|c|c|c|}
\hline \multirow{2}{*}{ Sensor } & \multicolumn{6}{|c|}{ Vertical motion (VM-718-15), mm } \\
\cline { 2 - 9 } & \multicolumn{6}{|c|}{ Normal crack opening width (PCE-MM200 and RSS-3-3), mm } \\
\cline { 2 - 8 } & $\mathbf{8 0 ~ k N}$ & $\mathbf{2 8 0} \mathbf{~ k N}$ & $\mathbf{4 8 0} \mathbf{~ k N}$ & $\mathbf{6 8 0} \mathbf{~ k N}$ & $\mathbf{8 8 0 ~ k N}$ & $\mathbf{1 0 8 0} \mathbf{~ k N}$ & $\mathbf{1 1 8 0} \mathbf{~ k N}$ \\
\hline VM-718-15 & - & 0.74 & 2.40 & 4.01 & 5.73 & 8.71 & 9.26 \\
\hline PCE-MM200 & - & 0.288 & 0.352 & 0.520 & 0.624 & 0.736 & - \\
\hline RSS-3-3* & - & 0.086 & 0.290 & 0.446 & 0.559 & 0.857 & - \\
\hline
\end{tabular}

* - to calculate the crack opening width using the RSS-3-3 sensor readings and the average annular crack spacing equal to $240 \mathrm{~mm}$

\section{Analysis of the strain-stress state and the sample destruction}

The compressive concrete strength according to the test results of cube samples of $100 \times$ $100 \times 100 \mathrm{~mm}$ and subsequent statistical processing corresponded to conditional class B27.3 with mechanical characteristics: $\mathrm{R}_{\mathrm{b}, \mathrm{n}}=20.2 \mathrm{MPa}, \mathrm{R}_{\mathrm{bt}, \mathrm{n}}=1.62 \mathrm{MPa}, \mathrm{E}_{\mathrm{b}}=31200 \mathrm{MPa}$. The following concrete values were used to compare the experimental values of relative deformations with characteristic values on two-line strain diagrams under conditions of short puncing action: $\varepsilon_{\mathrm{b} 1}=0.15 \%, \varepsilon_{\mathrm{b} 2}=0.35 \%, \mathrm{E}_{\mathrm{b}, \mathrm{red}}=13467 \mathrm{MPa}$ and reinforcement: $\varepsilon_{\mathrm{s} 0}=0.22 \%, \varepsilon_{\mathrm{s} 2}=2.5 \%, \mathrm{R}_{\mathrm{s}, \mathrm{n}}=500 \mathrm{MPa}, \mathrm{E}_{\mathrm{s}}=200000 \mathrm{MPa}, \mu_{\mathrm{s}}=0.5 \%$.

The plate in dimensions between the supporting contour and the column top is in a complex strain-stress state (SSS), characterized by the action of bending and torsional moments, and shear forces. In the upper zone, directly below the column, the bulk strainstress state occurs under the action of action of all strain tensor components.

The supporting contour perimeter has tearing and rotation of the side slab faces, reaching maximum values in the sample corners as they are punched, and therefore the vertical loads gradually start to be transferred to the supporting contour not through the 
entire sample support area, but only through the middle slab fragment parts. This aspect explains the different in sign and significance values of the relative deformations for individual bars. Table 1 according to sensor data shows 17, 18 and 9, 10, respectively.

When analyzing the resistive-strain sensor results Table 1 shows that the plastic material work begins at 4 th punching stage $(880 \mathrm{kN})$, when the values of relative deformations in sensors $1-10$ installed on half of the bars exceed $\varepsilon_{\mathrm{s} 0}=0.22 \%$. As for the other half of the bars at this punching stage, the reinforcement stresses do not exceed the yield strength. At the next stage, according to the resistive-strain sensors, the deformations of all the bars in this cross section, except for two on each side, pass into the plastic diagram area.

When analyzing the sensor values of concrete 29-32 Table 2 shows the different SSS pattern: there is a tension on the side of the compression concrete on one column side, then in the punching process it is transformed into compression, then in separate zones again into tension. As for the sensor samples 38 and 39, there is a similar situation, but without changing the stress signs: there are significantly less relative deformations in sensor 38 on the column face than in sensor 39, separated from the column at a distance close to the slab thickness. The explanation of these resistive-strain sensor values in the features of the SSS slab is the occurrence of local tension zones on the concrete surface around the perimeter of the column due to the indentation punching in two planes with the separation of the slab corners in diagonal directions and others. It should be noted that the maximum values of the concrete and reinforcement relative deformations during fracture are substantially less than its limiting values, which are specified above using state diagrams.

The relationship between the punch and the vertical motions in the slab center is given in Table 3; it is almost linear dependence in the range of 2-4 punching stages, and at $1^{\text {st }}$ and $5^{\text {th }}$ stages it is "steeper" and "gentler", respectively. The value of the maximum deflection at $6^{\text {th }}$ punching stage was fixed at a load in the range of $1080-1280 \mathrm{kN}$ immediately before the sample destruction without ensuring the holding for each stage of exposure at $20 \mathrm{~min}$. and the possibility of taking readings of all other sensors.

The sample destruction at the $6^{\text {th }}$ stage under a punch of $\sim 1180 \mathrm{kN}$ was brittle with the formation of a punching pyramid and was accompanied by strong cotton, associated with the separation surface formation in the concrete body and the sample separation into parts. The cracking pattern on the bottom slab face after the sample destruction is shown in Figure 3 ; there is a "through" crack (upper base of the punching pyramid) and local chipped concrete along the column perimeter shown in Figures 4 and 5 (b), respectively. The cracks formed on the lower and upper edges of the slab are shown in fig. 5 close up. It should be noted that there were almost no cracks on the lower slab face in the column dimensions due to the fact that the slab cross-section together with the column has significantly larger geometrical characteristics compared to a regular section. The distance between the annular cracks around the column varies from 100 to $300 \mathrm{~mm}$, the crack length has gaps and intersections with radial cracks, which in turn are almost straight along the supporting contour and around the column, are mostly curvilinear and can deviate significantly from the original direction.

The values of the normal crack opening width, obtained experimentally (according to an electron microscope) and analytically (according to relative reinforcement deformations) and given in Table 3, significantly differ only at the first punching stage; further, the obtained results show satisfactory convergence. 


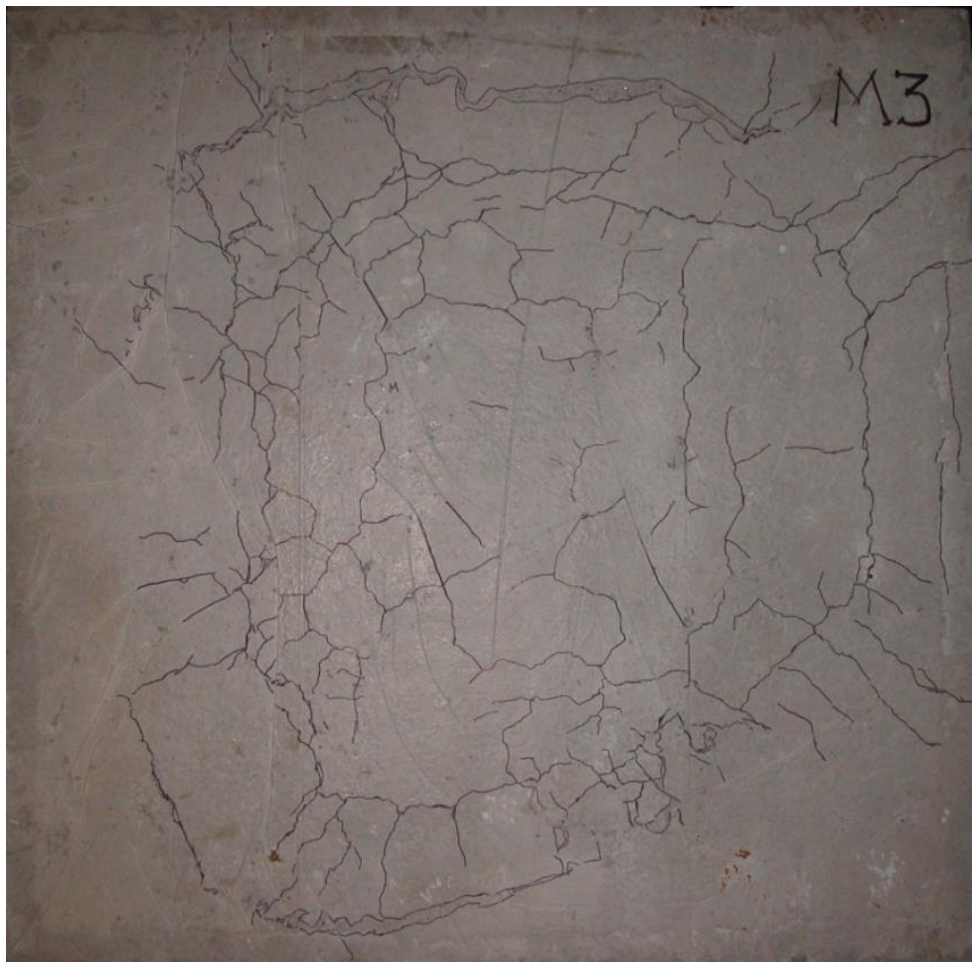

Fig. 3. Lower (tension) slab face

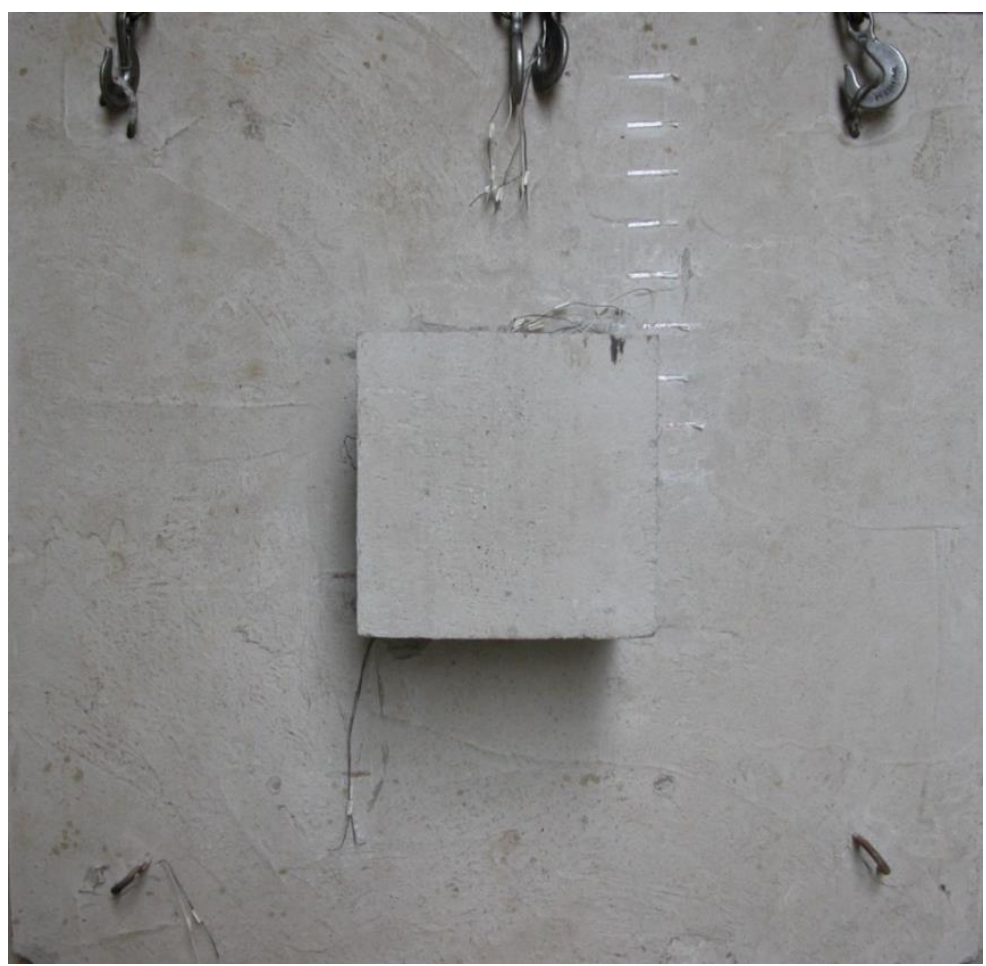

Fig. 4. Upper (compression) slab face 


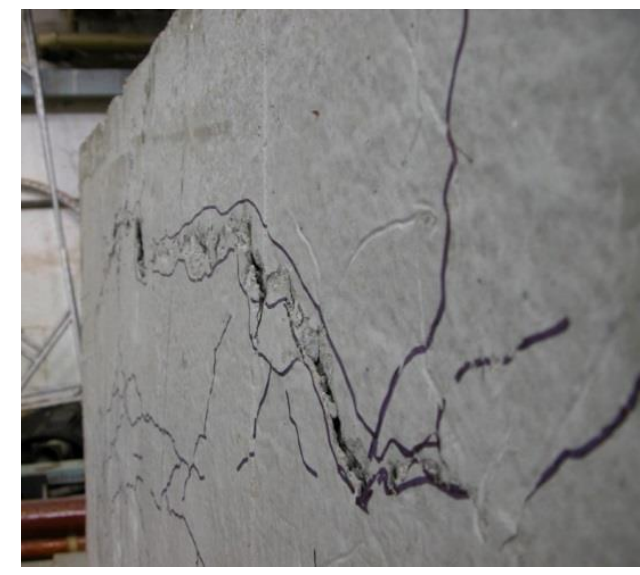

a) ring crack on the lower the slab face

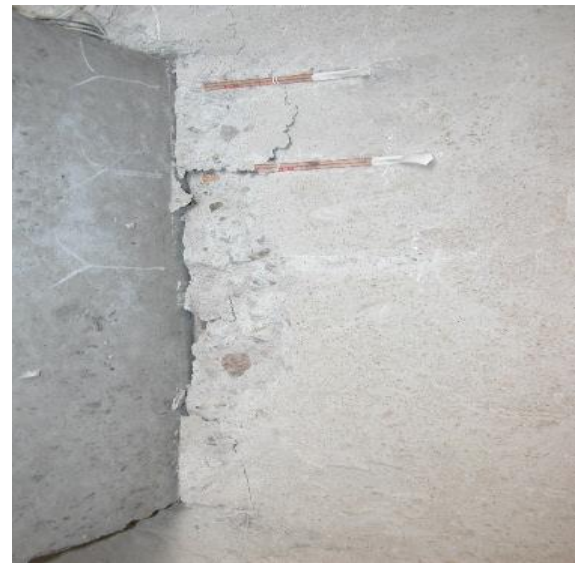

b) column cracks and spalls

Fig. 5. Cracks characterizing the punching pyramid

\section{Bearing punching capacity determination and analysis of results}

The bearing punching capacity according to the methods of SNiP 2.03.01-84* and SP 63.13330.2012, which are almost equivalent to each other, amounted to $962 \mathrm{kN}$. The punching coefficient, equal to the ratio of the calculated and destructive punches, was $962 / 1180=0.82$. When calculating punching according to the Eurocode 2 method, a fundamentally different approach is used; the maximum shall stresses (shall stresses are evenly distributed over the working section height) on two different contours: along the perimeter of the column faces and around the perimeter around the column at a distance of $2 \mathrm{~h}_{0}$ are compared with the maximum allowable stresses of the concrete shall for each circuit separately. The utilization factor for the column faces was $\mathrm{V}_{\mathrm{Ed} \text {,col }} / \mathrm{V}_{\mathrm{Rd} \text {, max }}=2.82 / 7.2$ $=0.39$ and on the outer contour it was $\mathrm{V}_{\mathrm{Ed}, \mathrm{ul}} / \mathrm{V}_{\mathrm{Rd}, \mathrm{c}}=1.06 / 0.80=1.33$. Thus, when comparing factors based on SNiP and Eurocode, the latter had a significant margin of $1.33 / 0.82=1.62$.

The reduced slab torque in the cross section with dimensions of $2000 \times 240(\mathrm{~h}) \mathrm{mm}$ on the column face with a load of $1180 \mathrm{kN}$, obtained on the basis of an improved technique [6], was $206 \mathrm{kN}^{*} \mathrm{~m}$, while the limiting torque of a given cross section for the most remote from the longitudinal reinforcement face $(\mathrm{a}=25+12=37 \mathrm{~mm})$, was equal to $193 \mathrm{kN} * \mathrm{~m}$. The flexural utilization factor, equal to the ratio of the limiting and reduced torques, was $206 / 193=1.07$. Obviously, in this case, the implementation of the punching mechanism could be triggered by the achievement of the limiting bearing slab capacity during torquing, and this factor is one of the prerequisites for improving the calculation punching method.

According to the experiment results, it was also found that the punching pyramid surface had a "fracture" on the column faces, i.e., the height of the truncated pyramid is somewhat less (by the height of the compression concrete near the column) than it is shown at Figures 5 (b) and 6. In tis case, it should be noted that the compression concrete height of the specified cross section in determining the limiting torque was $25.1 \mathrm{~mm}$ and slightly exceeded the corresponding vertical depth of the "through" crack along the column boundary during the punching pyramid formation. Moreover, the compression slab structure height is variable and increases with distance from the column while reducing the level of compressive stresses. Due to this fact, there is a need for more accurate 
determination of the compression concrete height in the column dimensions in the marginal stage.

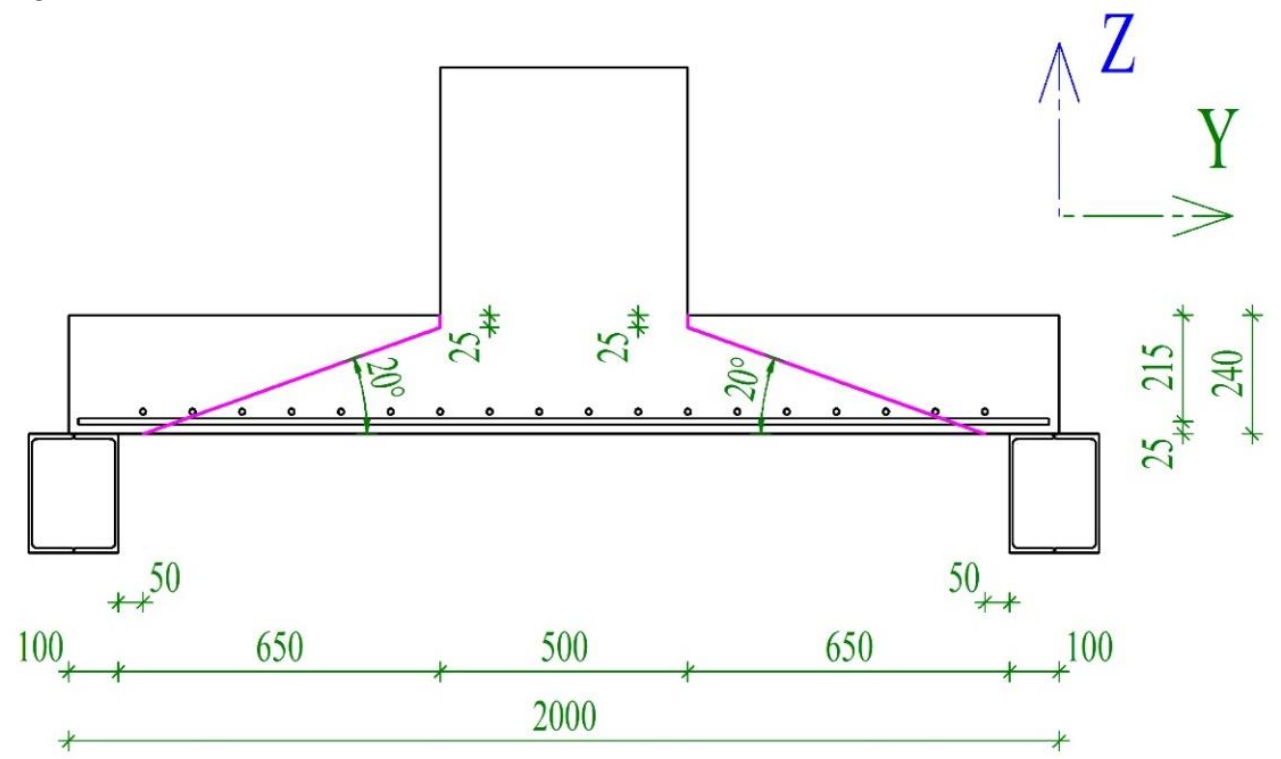

Fig. 6. Side pusing pyramid faces with "fractures"

The other important factor recorded experimentally and schematically and shown in Figure 6, concerns the punching pyramid inclination angles, which approximately amount to $-20^{\circ}$. Figures 3 and 5 (a) show the areas of the lower punching pyramid base using the double lines. It should be noted that there is a separation only in the upper and lower slab parts as shown in Figure 3, in the direction of the longitudinal reinforcement having a minimum protective layer, and there are no any such "through" cracks on the side slab parts as at the fracture beginning (after cotton) the pressure in the hydraulic station drops instantly, and only the load of the slab own weight continues and equipment, which is not enough for further destruction with full separation of the sample into parts. When using domestic regulatory punching calculation methods, the reduced pyramid inclination angles should obviously increase the bearing capacity, which is not confirmed by the obtained value of the breaking load and actually indicates the implementation of another slab structure destruction mechanism during the punching by Eurocode 2 that is one of the main assumptions that is used in domestic regulatory procedures and implies a uniform distribution of tension stresses across the punching pyramid surface, but nevertheless it is not true. The fallacy of such assumption can be easily illustrated in the following example; it is just necessary to take a paper sheet at two points closely spaced from each other, and begin tearing one part away from the other, applying force in opposite directions across the sheet, but it is impossible to distribute the load evenly along the break line. This is the fundamental difference of the destruction mechanism during punching from other types of destruction, which is primarily determined by the material properties such as various concrete resistance to tension and compression, as well as other factors incuding design, strength and stress level, and pucnnching mode. 


\section{Conclusions and the proposed method of calculating punching slabs}

According to the experiment results and the other data analysis, it is necessary to note some important aspects and suggest the following method development for calculating pushing slab reinforced concrete structures:

- the tested surface and floor slab fragments in the form of individual samples, freely supported along the contour, differ significantly from multi-span continuous analogs of the applicable SSS in the support zone;

- the inclination angle of the punching pyramid faces is variable and depends on many factors;

- the height of the compression concrete in the cross section of the column face support zone is variable and increases with distance from the column while reducing the level of compression stresses;

- the concrete surface near the column faces, associated with pressing the punch into the slab body has tension stresses;

- the normal crack opening width, calculated on the basis of electron microscope data, at the first punching stage differs significantly from the similar width, calculated analytically using the reinforcement resistive-strain sensors, starting from the second stage, the matching results can be considered satisfactory;

- the uniform distribution of tension stresses on the puncing pyramid surface does not correspond to reality;

- the punching mechanism trigger may lead to the transition of a number of tension reinforcing bars into the plastic work area and decrease critically in the height of the compression concrete due to the growth of normal and inclined cracks;

in general, it is possible to use Coulomb's law modification for the mathematical description of the punching mechanism at different SSS stages:

$$
F_{b, u l t}=v_{1} \cdot v_{2} \cdot v_{3} \cdot \sum_{i=1}^{n} x_{i} \cdot b_{i} \cdot\left(\sigma_{b i} \cdot \varphi_{p}+R_{b t}\right),
$$

where, $x_{i}$-height of the compression concrete at the i-th of the column face;

$b_{i}$ - width of the i-th column face;

$\varphi_{p}$ - concrete shear coefficient;

$\sigma_{b i}$ - horizontal normal stresses in concrete at the i-th column face;

$R_{b t}$ - concrete tensile strength;

$v_{1}-$ SSS coefficient: for III phase -1 , for I phase $-1 / \operatorname{Cos} 45^{\circ}=1.4$;

$v_{2}$ - punching coefficient: with static load -1 ;

$v_{3}$ - coefficient taking into account the constructive solution features: in case of no shear reinforcement -1 .

To calculate the height of the compression concrete $x_{i}$ at the i-th column face at SSS stage III, it is recommended to use the following assumption: a change in the height of the compression concrete in cross section is inversely proportional to the torque change:

$$
\mu(b)=1 / M(b)
$$

where, $\mu(b)$ is a coefficient of inverse transformation (maximum torque value to the corresponding minimum height of the compression concrete and vice versa);

$b-$ slab cross section width in the pushing area,

$M(b)=A_{0}+A_{1} \cdot b+A_{2} \cdot b^{2}$ - law of torque variation in the cross section.

To determine the law of the torque variation in the cross section, it is recommended to solve the problem of plate bending in a linear formulation using flat finite elements based on the Kirchoff theory. Further, based on the calculated reduced height of the compression 
concrete $x_{\text {red }}$ of the slab cross section in the punching zone and the corresponding reduced inverse transform coefficient $x_{\text {red }}$, the height of the compression concrete is calculated in the column dimensions:

$$
x_{c o l}=k_{x} \cdot \mu_{c o l}=\frac{x_{r e d}}{\mu_{r e d}} \cdot \sum_{i=1}^{n_{c}} \frac{\mu(b)_{c i}}{n_{c}}=\frac{R_{s} \cdot A_{s} \cdot \sum_{i=1}^{n_{c}} \frac{1}{M(b)_{c i} \cdot n_{c}}}{R_{b} \cdot b \cdot \sum_{i=1}^{n_{b}} \frac{1}{M(b)_{i} \cdot n_{b}}},
$$

where, $k_{x}=\frac{x_{r e d}}{\mu_{\text {red }}}-$ proportionality coefficient (const for $i$-th column face);

$x_{\text {red }}=R_{s} \cdot A_{s} /\left(R_{b} \cdot b\right)$ - reduced height of the compression concrete slab crosssection in the punching zone;

$\mu_{\text {red }}=\sum_{i=1}^{n_{b}} \frac{\mu(b)_{i}}{n_{b}}=\sum_{i=1}^{n_{b}} \frac{1}{M(b)_{i} \cdot n_{b}}-$ reduced inverse transform coefficient for slab cross section in the punching zone;

$\mu(b)_{i}$ - inverse transform coefficient in the punching zone;

$M(b)_{i}$ - torque in the $\mathrm{i}$-th final element in the pushing area;

$n_{b}$ - the number of finite elements of the slab section in the punching zone,

$\mu_{c o l}=\sum_{i=1}^{n_{c}} \frac{\mu(b)_{c i}}{n_{c}}=\sum_{i=1}^{n_{c}} \frac{1}{M(b)_{c i} \cdot n_{c}}-$ reduced inverse transform coefficient for the slab cross-section in the dimensions of the i-th column face;

$\mu(b)_{c i}-$ coefficient of inverse transformation in the column dimensions;

$M(b)_{c i}$ - torque in the i-th final element in the column dimensions;

$n_{c}$ - the number of finite elements of the slab section in the column dimensions.

As for the tested sample at SSS stage III, the formula (1) transforms to the form, and the bearing concrete punching capacity is:

$F_{b, u l t}=v_{1} \cdot v_{2} \cdot v_{3} \cdot u \cdot x_{c o l} \cdot\left(\sigma_{b i} \cdot \varphi_{p}+R_{b t}\right)=1 \cdot 1 \cdot 1 \cdot 2.0 \cdot 6.8 \cdot(20.2 \cdot 3.7+1.62)=1038.5$

where, $u=2.0 \mathrm{~m}-$ the column cross section perimeter;

$\mathrm{kN}, \quad(1.1)$

$x_{c o l}=6.8 \mathrm{~mm}-$ height of the compression concrete at the column faces;

$\varphi_{p}=3.7$ - concrete shear coefficient;

$\sigma_{b}=R_{b}=20.2 \mathrm{MPa}$ and $R_{b t}=1.62 \mathrm{MPa}$ - concrete resistance to compression and tension.

It should be noted that in this case the concrete shall coefficient is determined on the basis of solving the inverse problem with a known breaking load and is the subject of further research and experiments, as well as additional correction factors $v_{1}, v_{2}, v_{3}$ and the height of the compression concrete at the column faces $x_{c o l}$.

In the case of no significant slab torque influence on the construction SSS in the punching zone, the function (1) transforms to the classical form with the formation of a punching pyramid under $45^{\circ}$, and the bearing concrete capacity for concrete is:

$$
F_{b, u l t}=v_{1} \cdot v_{2} \cdot v_{3} \cdot u \cdot x_{c o l} \cdot\left(\sigma_{b i} \cdot \varphi_{p}+R_{b t}\right)=1.4 \cdot 1 \cdot 1 \cdot 2.0 \cdot 215 \cdot(0+1.62)=975.2
$$

where $v_{1}=1 / \operatorname{Cos} 45^{\circ}=1.4-\mathrm{SSS}$ coefficient;

$u=2.0 \mathrm{~m}-$ column cross section perimeter; 
$x_{c o l}=h_{0}=215 \mathrm{~mm}-$ working section height;

$\sigma_{b}=0 \mathrm{MPa}$ and $R_{b t}=1.62 \mathrm{MPa}-$ concrete compressive and tensile strength.

Due to this fact, the improvement of the current regulatory methods for calculating the punching and reinforcement requirements of slab reinforced concrete structures is quite an urgent task, requiring further analysis and synthesis of existing and new experiment and research results.

\section{References}

1. Karpenko N I, Karpenko S N (2012) Practical method of calculating reinforced concrete slabs for loading under various schemes. Concrete and reinforced concrete ed 5pp. 10-16.

2. Kodysh E N, Trekin N N, Nikitin I K (2011) Design of precast floor stab sections under increased loads. Industrial and Civil Engineering ed 2 pp. 24-26.

3. Klevtsov V A, Bolgov A N (2005) The actual work of the nodes of the beamless capless flat slab with columns during loading. Concrete and reinforced concrete ed 3 pp. 17-19.

4. Krasnoshchekov Y V, Komlev A A (2011) The strength of the beamless slab in the areas of connection with columns. Concrete and reinforced concrete ed 1 pp. 25-27.

5. Silantyev A S (2009) The VI International Conference of Students' and Young Scientists' works Problems of accounting for the actual node operation of beamless flat reinforced concrete slabs with columns. Basic science development prospects. (Publishing house of Tomsk Polytechnic University) pp. 726-729.

6. Trekin N N, Pekin D A (2014) The hidden metal capitals of beamless slabs. Industrial and Civil Engineering ed. 7 pp. 17-20. 